\title{
Desempenho, eficiência de utilização dos nutrientes e estrutura do trato digestório de pintos de corte alimentados na fase pré-inicial com rações de diferentes formas físicas
}

\author{
Ednardo Rodrigues Freitas ${ }^{1^{*}}$, Nilva Kazue Sakomura ${ }^{2}$, Fabiano Dahlke ${ }^{1}$, Fabiana Ramos \\ Santos $^{1}$, Nei André Arruda Barbosa ${ }^{1}$
}

\footnotetext{
1 Programa de Pós-Graduação em Zootecnia da FCAV, UNESP, Jaboticabal, SP.

2 Departamento de Zootecnia da FCAV, UNESP, Jaboticabal, SP. Via de Acesso Professor Paulo Donato Castellane, s/n, CEP: 14884-900, Jaboticabal, SP.
}

RESUMO - Este estudo foi realizado com o objetivo de avaliar o efeito da forma física da ração sobre o desempenho, a utilização dos nutrientes das rações e o desenvolvimento do trato disgestório de pintos de corte na primeira semana de vida. Foram utilizados 150 pintos machos Cobb distribuídos ao acaso em três tratamentos com cinco repetições de dez aves. Os tratamentos consistiram das formas físicas farelada, triturada e peletizada de uma ração pré-inicial comercial. Com exceção da moela, os órgãos do trato digestório e a estrutura morfométrica do intestino não foram influenciados pela forma física da ração. Maior digestibilidade do $\mathrm{N}$ foi obtida com a ração peletizada, enquanto a ração triturada possibilitou maior digestibilidade do EE. A energia metabolizável determinada para a ração farelada foi menor que a obtida nas demais formas físicas da ração. As aves alimentadas com ração farelada tiveram menor consumo de ração e ganho de peso e pior conversão alimentar. Ingeriram ainda menos energia, apresentaram menores retenções de proteína, gordura e energia corporal e utilizaram maior proporção da energia ingerida para produção de calor. As rações pré-iniciais na forma peletizada ou triturada possibilitam maior aproveitamento dos nutrientes da ração pelos pintos e melhor desempenho.

Palavras-chave: energia metabolizável, produção de calor, ração farelada, ração peletizada, ração triturada

\section{Performance, efficiency of nutrient utilization and gastrointestinal structures of broiler chick fed in prestarter phase with ratios with different physical form}

\begin{abstract}
This experiment was conducted to evaluate the effect of different physical form of pre-starter diet on performance, nutrient utilization and development of gastrointestinal tract of broiler chicks during the first week of age. A total of 150-day-old male broiler chicks was allotted to a completely randomized design with three treatments and five replicates of 10 birds each. Treatments consisted of three physical forms of a commercial pre-starter diet: mashed, crumbled and pressed into pellets. Except for gizzard, the other organs of the digestive tract and morphologic structures of the small intestine were not affected by the physical form of the diet. The highest $\mathrm{N}$ digestibility was observed in birds fed pellet diet, while crumbled diet showed the highest digestibility of EE. The metabolizable energy determined for mashed diet was lower than those determined for the other physical forms of the diet. Birds fed mashed diet had the lowest feed intake and body weight gain and the worse feed conversion. These birds also showed lower intake of energy and less protein, fat and energy retention in the body. They used a higher proportion of the energy consumed for heat production. Pre-starter diets prepared as pellets or crumbles allow better nutrient utilization and improve chick performance.
\end{abstract}

Key Words: crumbled diet, heat production, mash diet, metabolizable energy, pelleted diet

\section{Introdução}

A forma como os pintos são alimentados logo após a eclosão e nos primeiros dias de vida pode influenciar seu rendimento total, o que justifica a busca por rações que possibilitem crescimento máximo nessa fase. Segundo
Lilburn (1998), Penz (2001) e Toledo et al. (2001), as rações pré-iniciais devem ser formuladas com ingredientes de melhor qualidade para atender às exigências da fase observando-se a forma física.

Quando existe a possibilidade de escolha, as aves se alimentam com as partículas maiores e preferem a ração

Este artigo foi recebido em 10/4/2006 e aprovado em 19/7/2007. 
peletizada em relação à farelada (Moram, 1987; Nir etal., 1994). A seletividade do tamanho das partículas está diretamente relacionada às dimensões do bico (Moran, 1987). De acordo com Nir et al. (1994), os frangos de corte jovens selecionam as partículas da ração e preferem rações com partículas cujo diâmetro geométrico médio situa-se em torno de 0,7 e $0,9 \mathrm{~mm}$.

Por outro lado, o tamanho das partículas e a forma física da ração podem influenciar o consumo de alimento e a digestão dos ingredientes por alterarem a anatomia do trato digestório e/ou as secreções digestivas (Nir et al., 1994). Influências da granulometria dos ingredientes das rações e da peletização no desenvolvimento do trato digestório dos frangos de corte também foram relatadas por Shamoto \& Yamauchi (2000), Jensen (2001), Engberg et al. (2002), Dahlke et al. (2003) e López \& Baião (2004).

O uso de rações peletizadas na alimentação de frangos de corte promove melhor desempenho em relação às fareladas (Moran, 1987; Engberg et al., 2002; López \& Baião, 2004). Esse melhor desempenho tem sido associado ao aumento da digestibilidade dos nutrientes da ração (Moram, 1987; Zelenka, 2003) e ao aumento da densidade da ração, o que permite maior ingestão de nutrientes e, conseqüentemente, maior taxa de crescimento (Toledo et al., 2001; Engberg et al., 2002; McKinney \& Teeter, 2004).

Langhout (2001) e Penz (2001) afirmaram que rações pré-iniciais peletizadas (péletes de 1,5 a 2,0 $\mathrm{mm}$ ), proporcionam melhor desempenho em relação a essas rações na forma farelada.

Segundo Emmans (1987), além do crescimento da ave, a alimentação pode modificar as exigências energéticas e a eficiência do aproveitamento da energia pelos frangos de corte, principalmente a deposição de proteína e gordura. Entre os benefícios do uso de rações peletizadas para frangos de corte, tem-se observado aumento no aproveitamento da energia das rações (Jensen, 2001). De acordo com Nir et al. (1994), a peletização reduz o gasto de energia das aves para o consumo proporcionando redução na energia de mantença e aumentando a energia líquida de produção, o que favorece a energia disponível para o ganho. McKinney $\&$ Teeter (2004) observaram que, além de favorecer o consumo de ração, a peletização aumenta a eficiência de retenção da energia metabolizável aparente. Krabbe (2000) observou que a granulometria da ração pré-inicial influenciou os valores de energia metabolizável determinados e a retenção de nitrogênio e da MS na primeira semana.

Esta pesquisa foi realizada para avaliar os efeitos das formas físicas das rações pré-iniciais sobre o desenvolvimento do trato digestório, a utilização dos nutrientes das rações e o desempenho dos pintos de corte na primeira semana de vida.

\section{Material e Métodos}

Foram utilizados 150 pintos machos Cobb no período de 1 a 7 dias de idade. As aves foram alojadas em baterias com aquecimento e distribuídas em delineamento inteiramente ao acaso, com três tratamentos com cinco repetições de dez aves. Os tratamentos consistiram de formas físicas da ração: farelada, triturada (peletizada e depois moída) e peletizada (péletes de 1,8 mm) de uma mesma ração comercial (Mogiana Alimentos S.A).

As rações eram compostas de milho, farelo de soja, farinha de carne e ossos, calcário calcítico, suplemento mineral e vitamínico, aminoácidos e sal comum. De acordo com as análises realizadas em laboratório, conforme metodologias descritas por Silva \& Queiroz (2001), as rações continham, em média: $88,45 \%$ de MS; $2,87 \%$ de EE e $26,98 \%$ de PB na MS e $4.336 \mathrm{kcal}$ de EB por kg de MS. Os níveis calculados dos aminoácidos foram: 0,96\% de metionina + cistina; $1,30 \%$ de lisina, $0,73 \%$ de treonina e $0,19 \%$ de triptofano. O diâmetro geométrico médio das partículas (Zanotto \& Bellaver, 1996) de cada ração foi de 0,$407 ; 0,888$ e $1,725 \mathrm{~mm}$ para as rações farelada, triturada e peletizada, respectivamente.

Durante o período experimental, as aves receberam ração e água à vontade. Ao final da primeira semana, foram determinados o consumo de ração (g/ave), o peso médio final (g), o ganho de peso (g) e a conversão alimentar.

Para determinação dos coeficientes de digestibilidade da MS, do nitrogênio (N), do EE e dos valores de energia metabolizável aparente (EMA) e aparente corrigida (EMAn) das rações, foram instaladas bandejas sob as gaiolas para a coleta total das excretas no período de 3 a 7 dias de idade. Ao final do período experimental, as amostras das rações e excretas foram analisadas em laboratório para determinação dos teores de MS, EE, PB e EB segundo metodologias descritas por Silva \& Queiroz (2002). Com base nos resultados das análises, foram determinados os coeficientes de digestibilidade aparente e os valores de energia metabolizável (Matterson et al., 1965). A energia da ração retida como nitrogênio (ERN) foi calculada utilizando-se a fórmula: $\mathrm{ERN}=\mathrm{BN} \times 8,22$, em que: $\mathrm{BN}=$ balanço de nitrogênio do ensaio de metabolismo $(\mathrm{BN}=\mathrm{N}$ ingerido $-\mathrm{N}$ excretado); e 8,22 = quantidade de energia (kcal) contida em cada grama de nitrogênio retido pelas aves.

A determinação da proteína bruta retida (PBR), do extrato etéreo retido (EER), da energia retida (ER) e da produção de calor (PC) foi realizada segundo metodologia do abate comparativo (Farrel, 1974). Foram abatidas seis aves no início do experimento e duas aves de cada repetição, com pesos próximos aos pesos médios das parcelas ao 
final. Foram determinados os teores de MS, EE, PB e EB das amostras das carcaças segundo metodologias descritas por Silva \& Queiroz (2002) e, a partir dos teores médios de EE, PB e EB na carcaça, determinaram-se os conteúdos de gordura, proteína e energia corporal total ao início e ao final do período experimental. Por diferença, foi estimada a quantidade retida no período.

A produção de calor foi determinada por meio da fómula: $\mathrm{PC}=\mathrm{EMI}-\mathrm{ER}$, em que EMI = EMAn ingerida e $\mathrm{ER}=$ energia corporal retida. No cálculo da ingestão de EMAn, foi considerada a EMAn determinada para cada forma física da ração.

Outras duas aves de cada repetição foram sacrificadas para dessecação dos órgãos do trato digéstório. Foram retirados o proventrículo, a moela e os intestinos, que foram pesados para cálculo do peso relativo (em porcentagem do peso vivo). O intestino delgado de uma destas aves foi dividido nas porções duodeno, jejuno e éleo. Esses segmentos foram lavados com uma solução fisiológica salina para retirada de amostras de aproximadamente $5 \mathrm{~cm}$ da porção média de cada segmento. Depois de retirado, cada segmento foi submetido aos processos de fixação e preparação das amostras para análises descritas por Dahlke et al. (2003).

As análises morfométricas foram realizadas usando miscroscopia de luz e digitalizadas em um software para análise de imagem (Vídeo Plan, Zeiss ${ }^{\circledR}$ ). Aproximadamente 40 observações de cada repetição foram realizadas para determinação da profundidade média da cripta e do comprimento médio dos vilos em cada segmento.

Os dados foram analisados utilizando-se o módulo ANOVA do programa SAS (1996) e as médias foram comparadas pelo teste SNK (5\%).

\section{Resultados e Discussão}

Na avaliação dos órgãos do trato digestório (Tabela 1), as formas físicas da ração pré-inicial não influenciaram $(\mathrm{P}>0,05)$ o desenvolvimento do proventrículo e dos intestinos, medido pelo peso relativo desses órgãos. No entanto, as aves alimentadas com ração farelada apresentaram maior peso relativo da moela $(\mathrm{P}<0,05)$ em relação às alimentadas com ração triturada ou peletizada, que não diferiram entre si quanto ao desenvolvimento desse órgão.

Assim como nesta pesquisa, resultados de literatura (Nir et al., 1994; Jensen, 2001; Engberg et al., 2002; López \& Baião, 2004) têm comprovado que o tamanho relativo da moela de aves alimentadas com ração farelada é maior que o de aves alimentadas com ração peletizada. Segundo Jensen (2001), o mecanismo pelo qual a forma do alimento afeta o tamanho desse órgão não é perfeitamente compreendido. Entretanto, de acordo com Engberg et al. (2002), a menor quantidade de alimento na moela de aves alimentadas com ração peletizada pode ocasionar redução no peso da moela, em virtude da baixa estimulação para as ações mecânicas promovidas pela presença do alimento nesse órgão. Segundo López \& Baião (2004), o menor desenvolvimento da moela das aves alimentadas com rações granuladas está relacionado à maior taxa de passagem dessas rações, o que provocaria menor volume de alimento na moela e, conseqüentemente, menor atividade dos músculos.

Nas análises morfométricas (Tabela 1), observou-se que a forma física da ração não promoveu alterações $(\mathrm{P}>0,05)$ no comprimento dos vilos e na profundidade de criptas do duodeno, jejuno e íleo das aves. Esses resultados corroboram, em parte, as observações de Dahlke et al. (2003) de que a forma física da ração não influencia o comprimento dos vilos do duodeno de frangos de corte, entretanto, a profundidade das criptas é maior em aves alimentadas com ração peletizada. De acordo com Nir et al. (1994), quando fornecidas rações com partículas de mesmo tamanho, os péletes começam a se dissolver no proventrículo e chegam ao intestino totalmente dissolvidos, o que anula o efeito da forma física das rações na estrutura do duodeno. Essa hipótese pode justificar os resultados obtidos nesta pesquisa.

Os resultados do ensaio de metabolismo (Tabela 2) comprovaram que a forma física da ração pré-inicial influenciou $(\mathrm{P}<0,05)$ a digestibilidade do nitrogênio e do EE e os valores de energia metabolizável. A maior digestibilidade

Tabela 1 - Características do trato digestório de pintos de corte alimentados com rações pré-iniciais de diferentes formas físicas

\begin{tabular}{|c|c|c|c|c|}
\hline \multirow{2}{*}{$\begin{array}{l}\text { Porção do trato } \\
\text { digestório }\end{array}$} & \multicolumn{3}{|c|}{ Forma física } & \multirow[t]{2}{*}{ CV $(\%)$} \\
\hline & Farelada & Triturada & Peletizada & \\
\hline & \multicolumn{3}{|c|}{ Peso relativo ( $\%$ do peso corporal) } & \\
\hline Proventrículo & 1,10 & 1,06 & 1,10 & 6,05 \\
\hline Moela $^{1}$ & $4,78 \mathrm{a}$ & $4,26 b$ & $4,35 \mathrm{~b}$ & 5,52 \\
\hline \multirow[t]{2}{*}{ Intestinos } & 8,70 & 8,45 & 9,40 & 8,05 \\
\hline & \multicolumn{3}{|c|}{ Comprimento dos vilos $(\mu \mathrm{m})$} & \\
\hline Duodeno & 804 & 1.075 & 922 & 17,98 \\
\hline Jejuno & 743 & 705 & 768 & 10,65 \\
\hline \multirow[t]{2}{*}{ İleo } & 551 & 533 & 606 & 15,19 \\
\hline & \multicolumn{3}{|c|}{ Profundidade da cripta $(\mu \mathrm{m})$} & \\
\hline Duodeno & 147 & 148 & 147 & 3,01 \\
\hline Jejuno & 101 & 103 & 101 & 2,29 \\
\hline İleo & 70 & 71 & 71 & 1,00 \\
\hline
\end{tabular}

${ }^{1}$ Médias seguidas de letras distintas diferem significativamente pelo teste SNK $(P<0,05)$. 
Tabela 2 - Coeficientes de digestibilidade dos nutrientes e valores de energia em pintos de corte alimentados com rações pré-iniciais de diferentes formas físicas

\begin{tabular}{lrccc}
\hline \multirow{2}{*}{$\begin{array}{l}\text { Coeficiente de } \\
\text { digestibilidade }\end{array}$} & \multicolumn{3}{c}{ Forma física } & \multirow{2}{*}{ CV (\%) } \\
\cline { 2 - 4 } & Farelada & Triturada & Peletizada \\
\hline MS (\%) & 69,70 & 71,20 & 70,66 & 1,79 \\
$\mathrm{~N}^{1}(\%)$ & $64,09 \mathrm{~b}$ & $65,10 \mathrm{~b}$ & $70,06 \mathrm{a}$ & 3,38 \\
$\mathrm{EE}^{1}(\%)$ & $77,89 \mathrm{~b}$ & $89,37 \mathrm{a}$ & $78,61 \mathrm{~b}$ & 5,36 \\
$\mathrm{EMA}^{1}$ & $3.084 \mathrm{~b}$ & $3.282 \mathrm{a}$ & $3.214 \mathrm{a}$ & 1,89 \\
$\left.\mathrm{kcal}^{\mathrm{k}} \mathrm{kg} \mathrm{MS}\right)$ & & & & \\
$\mathrm{EMAn}^{1}$ & $2.867 \mathrm{c}$ & $3.052 \mathrm{a}$ & $2.952 \mathrm{~b}$ & 1,82 \\
$\left.\mathrm{kcal}^{1} \mathrm{~kg} \mathrm{MS}\right)$ & & & & \\
$\mathrm{ERN}^{1}(\mathrm{kcal})$ & $145,60 \mathrm{c}$ & $169,80 \mathrm{~b}$ & $190,20 \mathrm{a}$ & 2,69 \\
\hline
\end{tabular}

$\mathrm{EMA}=$ energia metabolizável aparente, $\mathrm{EMAn}$ = energia metabolizável aparente corrigida e ERN = energia retida como nitrogênio.

${ }_{1}$ Médias seguidas de letras distintas diferem significativamente pelo teste SNK $(P<0,05)$.

do nitrogênio foi obtida com a ração peletizada, enquanto a ração triturada possibilitou maior digestibilidade do EE. Conseqüentemente, esses resultados influenciaram os valores de EMA determinados para as rações, uma vez que a EMA determinada para a ração farelada foi significativamente menor em relação à das demais formas físicas, cujos valores não diferiram entre si $(\mathrm{P}>0,05)$. Os valores de EMAn determinados para ração triturada e peletizada também foram superiores ao determinado para ração farelada. Entretanto, diferentemente do observado para EMA, os valores de EMAn dessas rações diferiram entre si $(\mathrm{P}<0,05)$, o que pode estar relacionado às diferentes $(\mathrm{P}<0,05)$ retenções de energia como nitrogênio (ERN), principalmente entre os valores obtidos para rações triturada e peletizada.

Os resultados obtidos nesta pesquisa estão de acordo com as afirmações de alguns pesquisadores (Moran, 1987, Zelenka, 2003) de que um dos benefícios do uso de rações peletizadas para frangos de corte é o aumento no valor de EM das rações, em decorrência da maior digestibilidade dos nutrientes. De acordo com Zelenka (2003), o aumento no valor de EM pode compensar o custo com o processo de peletização.

Na primeira semana, observaram-se diferenças $(\mathrm{P}<0,05)$ no desempenho (Tabela 3 ) obtido entre as formas físicas para todas as variáveis avaliadas. As aves alimentadas com a ração farelada apresentaram menor $(\mathrm{P}<0,05)$ consumo de ração, menor ganho de peso e pior conversão alimentar em relação àquelas alimentadas com ração triturada e peletizada, que não diferiram entre si $(\mathrm{P}>0,05)$.

Esses resultados de desempenho estão de acordo com os encontrados na literatura, que apontam melhor desempenho quando a ração pré-inicial é fornecida na forma peletizada ou desintegrada. Langhout (2001) observou melhora no desempenho dos pintos alimentados com ração
Tabela 3 - Desempenho de pintos de corte na primeira semana alimentados com rações pré-iniciais de diferentes formas físicas

\begin{tabular}{lcccc}
\hline Item & \multicolumn{3}{c}{ Forma física } & CV (\%) \\
\cline { 2 - 4 } & Farelada & Triturada & Peletizada & \\
\hline $\begin{array}{l}\text { Peso final } \\
\text { (g/ave) }\end{array}$ & $167,64 \mathrm{~b}$ & $190,32 \mathrm{a}$ & $186,44 \mathrm{a}$ & 2,17 \\
$\begin{array}{l}\text { Ganho de } \\
\text { peso }^{1} \text { (g/ave) }\end{array}$ & $121,36 \mathrm{~b}$ & $144,12 \mathrm{a}$ & $139,76 \mathrm{a}$ & 2,70 \\
$\begin{array}{l}\text { Consumo } \\
\text { (g/ave) }\end{array}$ & $140,04 \mathrm{~b}$ & $153,92 \mathrm{a}$ & $149,68 \mathrm{a}$ & 3,32 \\
$\begin{array}{l}\text { Conversão } \\
\text { alimentar }\end{array}$ & $1,15 \mathrm{a}$ & $1,07 \mathrm{~b}$ & $1,07 \mathrm{~b}$ & 1,31 \\
& & & & \\
\hline
\end{tabular}

${ }^{1}$ Médias seguidas de letras distintas diferem significativamente pelo teste SNK $(P<0,05)$.

pré-inicial peletizada (péletes de $2 \mathrm{~mm}$ ) ou desintegrada resultante de péletes de $3 \mathrm{~mm}$ em relação aos que receberam dietas fareladas. De acordo com Penz (2001), o desempenho de frangos de corte alimentados com dieta pré-inicial peletizada (1,5 a 1,8 $\mathrm{mm}$ de diâmetro) foi melhor que o de frangos alimentados com dieta farelada. Embora o consumo de ração em aves alimentadas com ração triturada ou peletizada não tenha diferido significativamente no período de 1 a 7 dias de idade, Silva et al. (2004) obtiveram maior ganho de peso e melhor conversão alimentar para as aves alimentadas com ração triturada.

A forma física da ração pré-inicial influenciou $(\mathrm{P}<0,05)$ a quantidade de matéria seca e de gordura da carcaça (Tabela 4). As aves alimentadas com a ração farelada apresentaram menor quantidade de matéria seca e de gordura corporal em relação àquelas alimentadas com ração triturada ou peletizada, que não diferiram entre si $(\mathrm{P}>0,05)$ quanto a essas variáveis.

As aves alimentadas com ração farelada apresentaram menor $(\mathrm{P}<0,05)$ ingestão de energia e menores retenções de proteína, de gordura e de energia corporal em relação às alimentadas com as demais rações (Tabela 5). As aves alimentadas com ração triturada ingeriram mais energia $(\mathrm{P}<0,05)$ e apresentaram maiores retenções $(\mathrm{P}<0,05)$ de gordura e energia corporal em comparação àquelas alimentadas com ração peletizada.

A maior ingestão de energia metabolizável pelas aves alimentadas com ração triturada e peletizada pode ser atribuída ao maior consumo (Tabela 3 ) e à maior metabolização da energia (Tabela 2) quando essas rações foram utilizadas. Com isso, além do maior ganho de peso, houve maior acúmulo de gordura (Tabela 4) na carcaça dessas aves.

Segundo Jensen (2001), quando a energia é consumida além das necessidades para manutenção e crescimento de tecido muscular das aves, o excesso é depositado como gordura corporal, de modo que o acúmulo de gordura está 
Tabela 4 - Composição corporal aos 7 dias de idade dos pintos de corte alimentados com rações pré-iniciais de diferentes formas físicas (\% MN)

\begin{tabular}{lrrrr}
\hline \multirow{4}{*}{ Item } & \multicolumn{3}{c}{ Forma física } & CV (\%) \\
\cline { 2 - 4 } & Farelada & Triturada & Peletizada \\
\hline MS $^{1}(\%)$ & $24,66 \mathrm{~b}$ & $25,70 \mathrm{a}$ & $25,79 \mathrm{a}$ & 2,03 \\
$\mathrm{~PB}^{1}(\%)$ & 15,38 & 15,60 & 15,13 & 2,22 \\
EE $^{1}(\%)$ & $5,08 \mathrm{~b}$ & $5,92 \mathrm{a}$ & $6,14 \mathrm{a}$ & 4,49 \\
Cinzas $^{1}(\%)$ & 4,56 & 4,48 & 4,35 & 5,76 \\
\hline
\end{tabular}

${ }^{1}$ Médias seguidas de letras distintas diferem significativamente pelo teste SNK $(P<0,05)$.

Tabela 5 - Energia metabolizável ingerida (EMI), retenção de EE (EER), de PB (PBR) e de energia (ER) na carcaça, produção de calor $(\mathrm{PC})$ e relações EMR/EMI e PC/EMI em pintos de corte alimentados com rações préiniciais de diferentes formas físicas

\begin{tabular}{|c|c|c|c|c|}
\hline \multirow[t]{2}{*}{ Item } & \multicolumn{3}{|c|}{ Forma física } & \multirow[t]{2}{*}{ CV (\%) } \\
\hline & Farelada & Triturada & Peletizada & \\
\hline 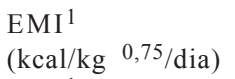 & $300,02 \mathrm{c}$ & $330,64 a$ & $316,54 b$ & 2,08 \\
\hline $\begin{array}{l}\mathrm{EER}^{1} \\
(\mathrm{~g} / \mathrm{kg} 0,75 / \mathrm{dia})\end{array}$ & $4,89 \mathrm{~b}$ & $6,60 \mathrm{a}$ & $6,77 \mathrm{a}$ & 5,53 \\
\hline $\begin{array}{l}\mathrm{PBR}^{1} \\
(\mathrm{~g} / \mathrm{kg} \quad 0,75 / \mathrm{dia})\end{array}$ & $14,42 \mathrm{c}$ & $16,44 \mathrm{a}$ & $15,43 b$ & 3,36 \\
\hline $\begin{array}{l}\text { ER } 1 \\
(\mathrm{kcal} / \mathrm{kg} \quad 0,75 / \mathrm{dia})\end{array}$ & $135,69 \mathrm{c}$ & $160,82 \mathrm{a}$ & $154,74 b$ & 3,51 \\
\hline 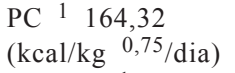 & 169,82 & 161,80 & 3,62 & \\
\hline ER/EMI ${ }^{1}(\%)$ & $45,24 b$ & $48,63 \mathrm{a}$ & $48,88 \mathrm{a}$ & 2,54 \\
\hline $\mathrm{PC} / \mathrm{EMI}^{1}(\%)$ & $54,76 \mathrm{a}$ & $51,37 \mathrm{~b}$ & $51,12 b$ & 2,30 \\
\hline
\end{tabular}

${ }^{1}$ Médias seguidas de letras distintas diferem significativamente pelo teste SNK $(P<0,05)$.

relacionado à ingestão de energia. Outro fato que pode explicar o acúmulo de gordura é que, com a peletização, a energia disponível para ave e a relação energia/proteína aumentam, uma vez que a proteína da dieta se mantém inalterada. Ampliando-se essa relação, a deposição de gordura é aumentada.

O maior acúmulo de gordura abdominal, visceral e na carcaça das aves alimentadas com ração peletizada em relação às alimentadas com ração farelada também foi observado por outros pesquisadores (Jensen, 2001; Lemme et al., 2006).

A relação ER/EMI foi menor $(\mathrm{P}<0,05)$ para as aves alimentadas com a ração farelada e não diferiu $(\mathrm{P}>0,05)$ entre os resultados obtidos com a ração triturada e peletizada.

A produção de calor (Tabela 5) não variou $(\mathrm{P}<0,05)$ entre as aves alimentadas com as diferentes rações, entretanto, a proporção da EMI utilizada para a produção de calor (PC/EMI) foi maior $(\mathrm{P}<0,05)$ nas aves alimentadas com ração farelada. Esses resultados indicam que as aves ali- mentadas com ração farelada foram menos eficientes em reter a energia ingerida, uma vez que gastaram proporcionalmente maior quantidade da energia ingerida para manutenção do metabolismo basal. Segundo Nir et al. (1994) e Jensen (2001), a peletização reduz o gasto de energia das aves para mantença, aumentando a energia líquida de produção, portanto, há mais energia disponível para o ganho. A peletização favorece a eficiência de retenção da energia metabolizável aparente, o que justifica a melhor conversão alimentar das aves alimentadas com rações peletizadas ou trituradas (McKinney \& Teeter, 2004; Lemme et al., 2006).

\section{Conclusões}

Com exceção da moela, que aumenta de tamanho relativo quando os pintos são alimentados com ração farelada, os demais órgãos do trato digestório avaliados e a estrutura morfométrica do intestino não são alterados pela forma física da ração pré-inicial. O fornecimento de rações préiniciais na forma peletizada ou triturada possibilita maior consumo, metabolização da energia e retenção da energia ingerida, o que favorece o desempenho dos pintos de corte na primeira semana de vida.

\section{Literatura Citada}

DAHLKE, F.; RIBEIRO, A.M.L.; KESSLER, A.M. et al. Effect of corn particle and physical form of the diet on the gastrointestinal structures of broiler chickens. Revista Brasileira de Ciência Avícola, v.5, p.61-67, 2003.

EMMANS, G.C. Growth, body composition and feed intake. World's Poultry Science Journal, v.43, p.208-227, 1987

ENGBERG, R.M.; HEDEMANN, M.S.; JENSEN, B.B. The influence of grinding and pelleting of feed on the microbial composition and activity in the digestive tract of broiler chickens. British Poultry Science, v.44, p.569-579, 2002.

FARRELL, D.J. General principles and assumptions of calorimetry. In: MORRIS, T.R.; FREEMAN, B.M. (Eds.) Energy requirements of poultry. Edinburgh: British Poultry Science, 1974. p.1-23.

JENSEN, L.S. Influência da peletização nas necessidades nutricionais das aves. In: ENCONTRO TÉCNICO SOBRE AVICULTURA DE CORTE DA REGIÃO DE DESCALVADO, 5., 2001, Descalvado. Anais... Descalvado: Associação dos Criadores de Frangos da Região de Descalvado, 2001. p.6-46.

KRABBE, E.L. Efeito do peso ao nascer, de níveis e formas físicas de administração de sódio e do diâmetro geométrico médio das partículas sobre o desempenho de frangos de corte até 21 dias de idade. Porto Alegre: Universidade Federal do Rio Grande do Sul, 2000. 252p. Tese (Doutorado em Zootecnia) - Universidade Federal do Rio Grande do Sul, 2000.

LANGHOUT, P.J. Feeding during the first week of life. International Poultry Production, n.1, p.7-10, 2001.

LEMME, A.; WIJTTEN, P.J.A.; Van WICHEN, J. et al. Responses of male growing broilers to increasing levels of balanced protein offered as coarse or pellets of varying quality. Poultry Science, v. 85, p.721-730, 2006.

LILBURN, M.S. Pratical aspects of early nutrition for poultry. Journal Applied Poultry Research, v.7, p.420-424, 1998. 
LÓPEZ, C.A.A.; BAIÃO, N.C. Efeitos do tamanho da partícula e da forma física da ração sobre o desempenho, rendimento de carcaça e peso dos órgãos digestivos de frangos de corte. Arquivos Brasileiro de Medicina Veterinária e Zootecnia, v.56, p. 214-221, 2004.

MATTERSON, L.D.; POTTER, L.M.; STUTZ, N.W. et al. The metabolizable energy of feed ingredients for chickens. Storrs: The University of Connecticut, Agricultural Experiment Station, 1965. 11p. (Research Report, 7).

McKINNEY, L.J.; TEETER, R.G. Predicting effective caloric value of nonnutritive factors: I. pellet quality and II. prediction of consequential formulation dead zones. Poultry Science, v.83, p.1165-1174, 2004.

MORAN, E.T. Pelleting affects feed and its consumption. World Poultry, v.5, p.30-31, 1987.

NIR, I.; TWINA, Y.; GROSSMAN, E. et al. Quantitative effects of pelleting on performance, gastrointestinal tract and behavior of meat-type chickens. British Poultry Science, v.35, p.589-602, 1994.

PENZ, A.M. Recentes avanços na nutrição de frangos de corte. In: ENCONTRO TÉCNICO SOBRE AVICULTURA DE CORTE DA REGIÃO DE DESCALVADO, 5., 2001, Descalvado. Anais... Descalvado: Associação dos Criadores de Frangos da Região de Descalvado, 2001. p.15-26.

SHAMOTO, K.; YAMAUCHI, K. Recovery responses of chick intestinal villus morphology to different refeeding procedures. Poultry Science, v.79, p.718-723, 2000.
SILVA, D.J.; QUEIROZ, A.C. Análise de alimentos: métodos químicos e biológicos. 3.ed. Viçosa, MG: Editora UFV, 2002. $165 \mathrm{p}$.

SILVA; J.R.L; RABELLO; C.B.; DUTRA JR., W.M. et al. Efeito da forma física e do programa alimentar na fase préinicial sobre desempenho e características de carcaça de frangos de corte. Acta Scientiarum.Animal Sciences, v.26, p.543551,2004

STATISTICAL ANALYSIS SYSTEM - SAS. SAS/STAT: user's guide, version 6., 11.ed. Cary: 1996. 842p.

TOLEDO, R.S.; VARGAS JR., J.G.; ALBINO, L.F.T. et al Aspectos práticos da nutrição pós-eclosão: níveis nutricionais utilizados, tipos de ingredientes e granulometria da dieta. In: CONFERÊNCIA APINCO DE CIÊNCIA E TECNOLOGIA AVÍCOLAS, 2001, Campinas. Anais... Campinas: Fundação APINCO de Ciência e Tecnologia Avícolas, 2001. p.153167.

ZANOTTO, D.T.; BELlAVER, C. Métodos de determinação da granulometria de ingredientes para uso em rações de suínos e aves. Concórdia: EMBRAPA-CNPSA, 1996. p.1-5. (Boletim Técnico, 225).

ZELENKA, J. Effect of pelleting on digestibility and metabolizable energy of poultry diets. In: EUROPEAN SYMPOSIUM ON POULTRY NUTRITION, 14., 2003, Lillehammer. Proceedings.. Lillehammer: World's Poultry Science Association, 2003. p. $127-128$ 